ian population is composed of diverse social groups with different, sometimes conflicting interests, unlike armed organizations and/or defense forces.

The civilian population, naturally, is not prepared to cope with such threats and its resilience and ability to cope depends mainly on the national response in raising the awareness and providing the civilian population with constant information. This is a challenge that the Home Front Command is facing.

One of the major tools in facing the challenge and preparing the civilian population to cope with emergencies is the risk communication program. "Risk communication" has a unique meaning in the Home Front Command. For most of the world, the term risk communication means information exchange, training, information management, etc. In the Home Front Command risk communication is referred to as more of a process rather than an act. It is an ongoing process which is aimed to motivate, educate, stimulate, and induce the public to lifesaving behaviors or mechanisms in case of an emergency. It achieves this goal by providing the civilian population with information, training, guidance, and support, year-round.

The concept of risk communication is based on the necessary and vital association between the actions of providing information, training, guidance, and support and the effectiveness and efficiency of the behavior of the public in daily life and in emergency situations--behavior that has the power to save lives.

This concept offers tools based on the theoretical and practical knowledge of the Home Front Command in providing the public with information and guidance with the best results.

There are many questions associated with "information and guidance", such as: should one provide with all the information and when? What should one say? How? When? What are the features of effective and efficient information? What are the most central information channels? Does one react to the source of the threat alone or should he or she take in consideration the public and the individual reaction?

This presentation will address the characteristics of the Israeli social environment in implementing/conducting risk communication to the public; the Isracli society; the media; the emergency organizations; the enemy; the principals and methods in conducting effective risk communication in everyday and in emergency; and the process of risk communication from the young to the old.

Keywords: civilian population; Home Front Command; information; Israel; risk communication Prebosp Disaster Med

\section{Management of Non-Conventional Events}

Planning and Preparedness for Hazardous Substance

Releases in India

V. Kapil, ${ }^{1}$ H. Falk, ${ }^{1}$ P. Ruckart; ${ }^{1}$ A. Dewan, ${ }^{2}$ M. Orr; ${ }^{1}$

J. Madden ${ }^{1}$

1. Centers for Disease Control and Prevention, Atlanta, Georgia USA

2. Indian Council of Medical Research, New Dehli, India

Introduction: The Indo-US Collaboration on Environmental and Occupational Health and Injury Prevention and Control was established by the US Department of Health and Human Services/Centers for Disease Control and Prevention (HHS/CDC) and the Indian Ministry of Health and Family Welfare (MOHFW) in 2002 to promote collaborative research, training, and capacity building in various areas of environmental and occupational health including emergencies. A related bi-national agreement focusing on injury prevention and trauma system enhancement recently was developed and implemented. The agreements include joint efforts to enhance emergency preparedness and responses for accidental or disaster-related releases of hazardous substances. The history and evolution of this binational agreement will be discussed as a model for public health preparedness cooperation with low- and middleincome countries.

Methods: Under the auspices of this agreement, the CDC worked closely with partner agencies in India to conduct surveillance of hazardous substance releases in the State of Gujarat. This surveillance was modeled after the US Hazardous Substances Emergency Events Surveillance (HSEES) system that CDC utilizes in 14 states. Data from 2005-2007 were collected in India and entered into a secure Web-based application. Information collected for each event included the type of release, location and industry involved in the event, number of victims, hospitalizations, deaths, evacuations, and contributing factors for the event.

Results: Results for hazardous substance releases in Gujarat State will be presented and the Indian experience will be compared with relevant US data. Joint training programs for the acute management of hazardous substance exposures will be described and discussed.

Conclusions: Both India and the US face numerous common challenges in preparing for a variety of environmental emergencies and disasters resulting in mass casualties. Potential threats include chemical agents, biological or radioactive substance releases, and other similar events that may result in a large surge of patients to health care facilities. The findings from Gujarat have implications for preparedness and response planning for similar events in many low- and middle-income countries.

Keywords: capacity building; hazardous materials; India; lowincome country; preparedness

Prebosp Disaster Med 